\title{
La recesión de 2009 y la expansión 2010-2012 en las entidades federativas de México
}

\section{9 recession and expansion from 2010 to 2012 in the states of Mexico}

\author{
Alfredo Erquizio Espinal ${ }^{\star}$ y Roberto Ramírez Rodríguez ${ }^{* \star}$
}

Resumen

El artículo examina las fases de recesión y expansión por las que transitó México en los últimos cuatro años y explica en particular las causas de la diversidad de las manifestaciones regionales de la Gran Recesión de 2009. Se utiliza una tipología regionalsectorial, la cual formula nuevos índices basados en la hipótesis de Mitchell acerca de los ciclos clásicos y propone una ecuación de ciclo regional inspirada en la metáfora de Frish acerca del mecanismo cíclico. Así, se comprueba que el perfil sectorial de las entidades federativas determina dicha diferenciación, pues las entidades federativas más manufactureras fueron las más afectadas y las caracterizadas principalmente por su carácter agrícola o minero, menos. Palabras clave: ciclos económicos regionales, economía mexicana, economía regional, recesiones regionales, crecimiento económico.

\section{Abstract}

The article examines the recession and expansion phases for which transited Mexico in the past four years and in particular explains the causes of regional diversity of manifestations of the Great Recession of 2009. It uses regional-sectoral typology, formulated new indices based on Mitchell hypothesis about classic cycles and proposes a regional cycle equation inspired Frish metaphor about cyclical mechanism. This verifies that the sectoral profile of the states determines such differentiation, since most manufacturing states were most affected and characterized mainly by agricultural or mining character, they were less.

Keywords: regional economic cycles, Mexican economy, regional economy, regional recessions, economic growth.

Recibido el 26 de marzo de 2013.

Aprobado el 25 de abril de 2014.

* Departamento de Economía de la Universidad de Sonora. Correo electrónico: oerquiz@guaymas.uson.mx

** Departamento de Economía de la Universidad de Sonora. Correo electrónico: robecar2@rtn.uson.mx 


\section{Introducción}

La tasa de crecimiento del Producto Interno Bruto (Рів) de la economía mexicana descendió $4.7 \%$ en 2009, y entre 2010 y 2012 ascendió en promedio anual a un ritmo de $4.3 \%$. Las fases de recesión y expansión del ciclo económico clásico ${ }^{1}$ que dichas tasas sintetizan, se manifestaron de una manera claramente diferenciada a escala regional. Ello se debió tanto al distinto grado de vinculación de las entidades federativas con el ciclo de Estados Unidos de América (EE. UU.), como al diferente perfil productivo sectorial que las caracteriza.

Para demostrarlo se examinan las fases de recesión y expansión por las que transitaron las entidades federativas de México en los últimos años, y se explica en particular la diversidad recesiva regional en $2009 .{ }^{2}$ Lo que se realiza mediante la formulación y el cálculo de nuevos índices basados en la hipótesis de Mitchell acerca de los ciclos clásicos, la proposición y estimación de una ecuación de ciclo regional inspirada en la metáfora de Frish acerca del mecanismo cíclico.

La literatura acerca de los ciclos económicos nacionales y regionales en México, tanto desde la perspectiva de los ciclos clásicos como de los ciclos de crecimiento, se puede distinguir por la temática abordada: cronología de las fases del ciclo, hechos estilizados del ciclo, sincronización con el ciclo internacional e índices para medirlos y anticiparlos.

Así, acerca de los ciclos nacionales, diferentes autores establecen una cronología: Erquizio (2006a, 2007a), Erquizio (2007a), Cámara (2008), Heath (2011) y Calderón (2012). Revelan hechos estilizados: Mejía (1999),

${ }^{1}$ Hay dos enfoques para analizar las fluctuaciones económicas: el de los ciclos clásicos (business cycle) inspirado en Mitchell y el de los ciclos de crecimiento (growth cycle) basado en Lucas. Ver más adelante las dos definiciones de "ciclo".

${ }^{2}$ La expansión del ciclo económico iniciada en 2010 aún no concluye, pues dicha fase sólo se cierra con una nueva recesión. Las tasas de crecimiento del PIB en 2010, 2011 y 2012 fueron $5.1 \%$, 3.8\% y 3.9\% respectivamente. Los datos anuales oficiales del PIB del 2013 no están disponibles al momento de cerrar este artículo (16 de enero de 2014), aunque la mayoría de las previsiones oscilan alrededor de $1 \%$ de crecimiento del рів, lo que indicaría que la expansión — si bien ahora es más lenta- sigue en curso. De allí que no se pueda todavía proceder a un examen de la expansión en las entidades federativas de México que sea análogo al propuesto aquí para la recesión del 2009. 
Agénor, Mc Dermott y Prasad (2000), Torres (2002), Mejía (2003) y Cuadra (2008). Miden la sincronización internacional de los ciclos a nivel sectorial: Cuevas, Messmacher y Werner (2003), Mejía, Gutiérrez y Pérez (2006), y Mejía, Gutiérrez y Farías (2006). Proponen índices para representar el ciclo y anticiparlo: Moreno (1995), Erquizio (2001, 2006a).

Los ciclos económicos a escala regional, los identifican mediante índices coincidentes mensuales de varias entidades federativas, y encuentran que difieren entre sí y con respecto del índice nacional: Erquizio (2006b, 2008). Establecen la sincronización nacional e internacional de los ciclos regionales: Del Negro y Ponce (1999) y Ponce (2001), quienes sostienen que las fluctuaciones nacionales son el origen principal de las estatales; mientras que Cuevas et al. (2003) argumentan que las fluctuaciones cíclicas de la zona sur del país son en gran medida independientes, que los estados de la zona centro son más sensibles a las perturbaciones fiscales y demás de naturaleza idiosincrática y que los estados del norte experimentan fluctuaciones sincronizadas a la dinámica de la economía estadunidense; asimismo, Mejía y Campos (2011) y Mejía (2011) analizan la sincronización nacional e internacional de los ciclos estatales y afirman que los estados más grandes explican la dinámica del ciclo nacional y que la sincronización internacional se limita a un conjunto de entidades federativas del norte y centro del país; y finalmente, Delajara (2011b, p. 22) encuentra una mayor reacción de la actividad económica en el norte a los cambios en la actividad económica en EE. UU. en relación con el resto de las regiones, de tal suerte que existe una gradiente norte-sur en la "que la elasticidad promedio para los estados del norte, centro, centro norte y sur es $1.05,0.68,0.54$ y 0.37 , respectivamente".

Lo anterior revela que hay un consenso en que los ciclos económicos nacionales efectivamente se manifiestan de una manera diversa a escala regional y que una de las causas de ello es el distinto grado de vinculación de las economías regionales con el ciclo internacional representado por el de Estados Unidos, con lo cual queda establecida la importancia de los factores exógenos como causa de la diversidad cíclica regional. Sin embargo, se echa de menos la consideración de los factores endógenos de dicha diversidad. En ese sentido, Erquizio (2010a), para analizar las causas de la recesión de 2001, añade al factor exógeno, representado por la correlación de la tasa de crecimiento del PIBE con la tasa de crecimiento del PIB 
de EE. UU., la presencia de un factor endógeno que sería el que revela el índice semejanza recesiva que se propone en dicho artículo; mientras que en Erquizio (2010b) para explicar las causas de la diversidad recesiva regional se utiliza además del factor exógeno mencionado, el porcentaje de participación de la manufactura en el PIBE como variable que representa el factor endógeno determinante de dicha diversidad. Sin embargo, en ambos textos, si bien se logran resultados de significación estadística aceptable para los factores señalados, ello se puede mejorar como se propone en este artículo.

Ya han transcurrido cuatro años desde la recesión de 2009, la fase actual del ciclo económico es de expansión y acaban de publicarse cifras oficiales del pibe al 2012; así, es posible revisar lo acontecido en la recesión de 2009 y la expansión de 2010-2012 en las entidades federativas de México. Y es que salvo análisis particulares en los trabajos de Erquizio y Gracida (2010), Díaz y Mendoza (2012) y Mejía, Ochoa y Díaz (2013), quienes revisan la recesión y la recuperación económica en los estados de Sonora y Sinaloa, los estados de la frontera norte y del estado de México, respectivamente, y el que realiza Delajara (2013) para todo el país con cifras del empleo estatal, no hay exámenes de lo ocurrido en las 32 entidades federativas de México en los últimos años, desde la perspectiva de los ciclos clásicos, de allí la pertinencia de este artículo.

Por tanto, el aporte aquí es que se revisa la recesión de 2009 y la expansión de 2010-2012 en México con base en la información anual del PIBE a precios de 2008, considerando la relación de estas fases con el entorno internacional; vinculando la diversidad de las manifestaciones regionales de dichas fases del ciclo económico nacional con el perfil productivo sectorial regional; y proponiendo una ecuación del ciclo económico regional que permite ponderar el papel de dichos factores exógenos y endógenos en la explicación de la diversidad recesiva regional en 2009.

Así, lo que sigue se organiza en apartados: en el primero se examina la vinculación entre los ciclos económicos de Estados Unidos y México a nivel agregado y sectorial considerando tanto la recesión de 2009 como la expansión de 2010-2012 que marca el inicio de una nueva fase del ciclo económico en ambos países; en el segundo apartado se revela la diversidad cíclica regional en la recesión de 2009 y la expansión de 2010-2012 
y se la contrasta con una tipología regional que atiende al perfil productivo sectorial-regional; en el tercer apartado se propone una ecuación de ciclo regional que da cuenta de la diversidad recesiva regional; finalmente, se presentan las principales conclusiones.

\section{Los ciclos económicos de Estados Unidos y México}

Burns y Mitchell (1946, p. 3) proporcionan la definición de los ciclos económicos clásicos como:

[...] un tipo de fluctuación que se encuentra en la actividad económica agrega$d a$ de las naciones que organizan su trabajo, principalmente en empresas de negocios: un ciclo económico consiste en lapsos de ascenso que ocurren al mismo tiempo en muchas actividades económicas, seguidas de lapsos de descenso de igual modo generales, compuestos por fases de crisis, recesión y reavivamiento que se resuelven en un nuevo ascenso en el ciclo siguiente; esta secuencia de cambios es recurrente pero no periódica; la duración del ciclo económico varía entre algo más de un año hasta diez o doce años; y no son divisibles en ciclos más cortos de similar carácter y amplitud. ${ }^{3}$

Considerando que se trata de un movimiento al ascenso seguido de un movimiento al descenso, los periodos del ciclo son dos:

${ }^{3}$ Esta definición de ciclo clásico contrasta con la de Lucas (1985, p. 47) quien al proponer un nuevo programa de investigación acerca de la teoría del ciclo, los define como ciclos de crecimiento: "Permítaseme comenzar a dar forma a la discusión haciendo un repaso de las condiciones cualitativas esenciales de las series temporales económicas que hemos venido a denominar ciclos económicos. Desde un punto de vista técnico, los movimientos en torno a la tendencia del producto nacional bruto de cualquier país pueden ser perfectamente descritos por una ecuación en diferencias finitas de muy bajo orden afectadas estocásticamente. Estos movimientos no reflejan ninguna uniformidad, ni en lo referente a la amplitud ni en lo tocante a la periodicidad, lo que implica que no se asemejan a los movimientos cíclicos determinísticos que a veces se dan en las ciencias naturales. Esas regularidades observadas son 'los co-movimientos' entre diferentes series temporales agregadas". Una discusión detallada de los enfoques de ciclo clásico (business cycle) o de Mitchell y de ciclo de crecimiento (growth cycle) o de Lucas, se puede consultar en el capítulo 1 de Erquizio (2006a). 
- Ascenso del ciclo es el lapso que media entre el valle inicial $\left(\mathrm{V}_{\mathrm{i}}\right)$ y el pico (P) y que usualmente se denomina "recuperación" y/o "expansión". ${ }^{4}$

- Descenso del ciclo es el lapso que media entre el pico $(\mathrm{P})$ y el valle final $\left(\mathrm{V}_{\mathrm{f}}\right)$ y que usualmente se denomina "recesión".

La caracterización de los ciclos nacionales y regionales requiere examinar tres rasgos de sus recesiones: ${ }^{5}$

- Cronología: fechas en que ocurren el pico y su valle final expresadas en años, trimestres o meses.

- Duración: número de años, trimestres o meses que transcurren entre el pico del ciclo y su valle final.

- Amplitud o profundidad: ${ }^{6}$ calculada mediante la siguiente fórmula: [(Valor del indicador del ciclo en el valle final / Valor del indicador del ciclo en el pico)-1]*100.

Para identificar los ciclos es necesario elegir un ciclo específico o grupo de éstos, del conjunto de variables que se mueven simultáneamente al ascenso y al descenso en los ciclos económicos. Dicha variable se denomina ciclo de referencia, y aunque es preferible utilizar indicadores cíclicos de alta frecuencia como los mensuales, en ausencia de ellos se puede recurrir a los trimestrales y aun a los anuales.

Si se examina la evolución de los PIв trimestrales desestacionalizados de Estados Unidos y México, en la figura 1 se observa:

${ }^{4}$ La recuperación concluye cuando el valor del indicador representativo del ciclo supera el valor alcanzado en el pico del ciclo anterior, a partir de entonces se inicia la expansión, la cual termina cuando se inicia la recesión. Puesto que la tasa de crecimiento del PIв de México en 2010 fue de 5.1\%, el PIв en dicho año recuperó su nivel previo a la caída de $4.7 \%$ del año 2009, y desde entonces México está en la fase de expansión de su ciclo económico (ver figura 1).

${ }^{5} \mathrm{Al}$ definir los picos y valles de las recesiones de ciclos sucesivos, se está fechando también a las recuperaciones y/o expansiones, pues el valle final $\left(\mathrm{V}_{\mathrm{f}}\right)$ de una recesión es el valle inicial $\left(\mathrm{V}_{\mathrm{i}}\right)$ del nuevo ciclo, a partir del cual se inicia una expansión que culmina en un pico $(\mathrm{P})$, de tal suerte que se tiene la siguiente secuencia: $\mathrm{V}_{\mathrm{i}}-\mathrm{P}-\mathrm{V}_{\mathrm{f}}-\mathrm{P}-\mathrm{V}_{\mathrm{f}}-\mathrm{P}-\mathrm{V}_{\mathrm{f}}-\mathrm{P}-\mathrm{V}_{\mathrm{f}}$ ${ }^{6}$ La amplitud de la expansión se mide así: [(Valor del indicador del ciclo en el pico / Valor del indicador del ciclo en el valle inicial) -1] *100. 
Figura 1. Ciclos económicos clásicos de México y EE. UU. pib trimestral desestacionalizado, millones de pesos del 2003 y miles de millones de dólares del 2005

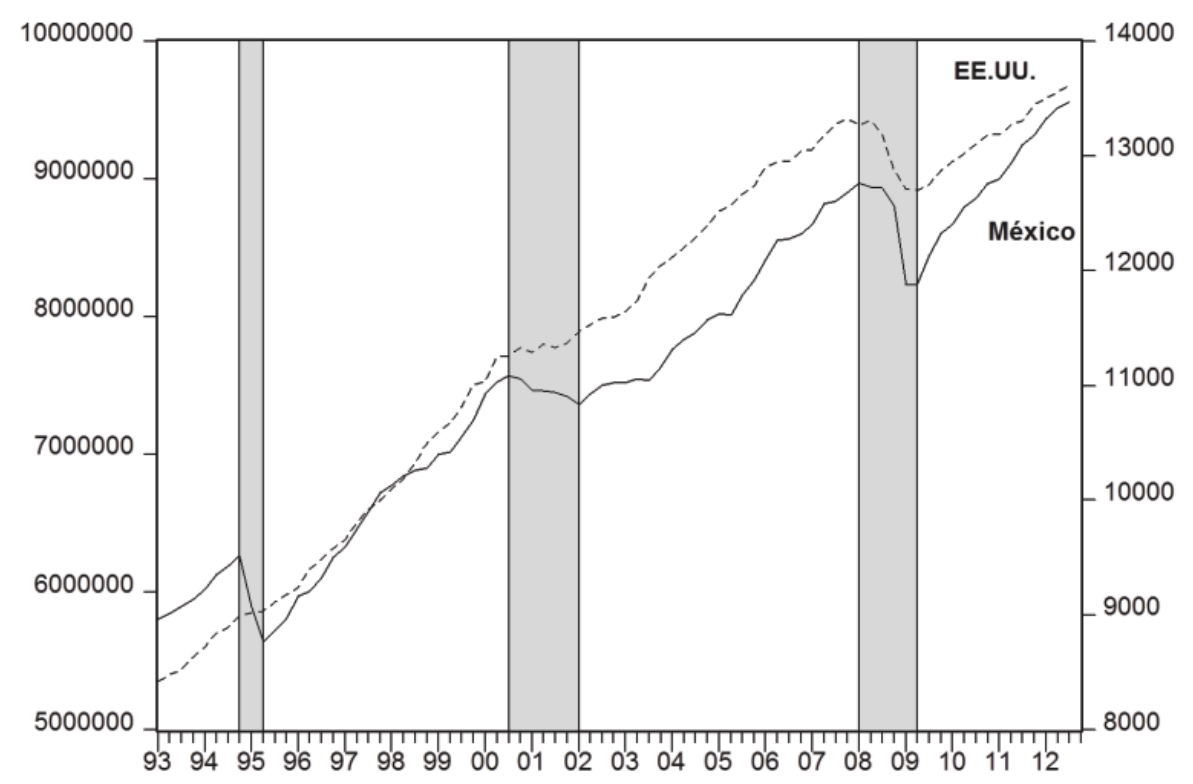

Fuente: Elaboración propia en base a datos del INEGI.

- la sincronía de sus recesiones en 2009 y de las respectivas expansiones en 2010-2012.

- la no sincronía entre la recesión mexicana de 1995 respecto de lo que ocurría en dicho año en Estados Unidos.

Mientras que en 2001 la sincronía entre ambas recesiones no es detectable con la información de la producción agregada, sí lo es con los índices de la producción industrial mostrados en la figura 2.

Puesto que las recesiones recientes de la economía mexicana están cada vez más vinculadas al ciclo de la economía de Estados Unidos, es interesante medir el patrón de movimiento común de una variable $\mathrm{c}_{\text {mex }}$ que represente el ciclo de México o los ciclos específicos de sus sectores y regiones, con respecto de otra variable que represente el ciclo de EE. UU. $\mathrm{c}_{\text {eeuu }}$ mediante los coeficientes de correlación P contemporánea, adelantada y rezagada entre dichas variables: 
Figura 2. Ciclos económicos clásicos de México y EE. UU. Índices de Producción Industrial desestacionalizados (base 2003=100) y (base 2007=100)

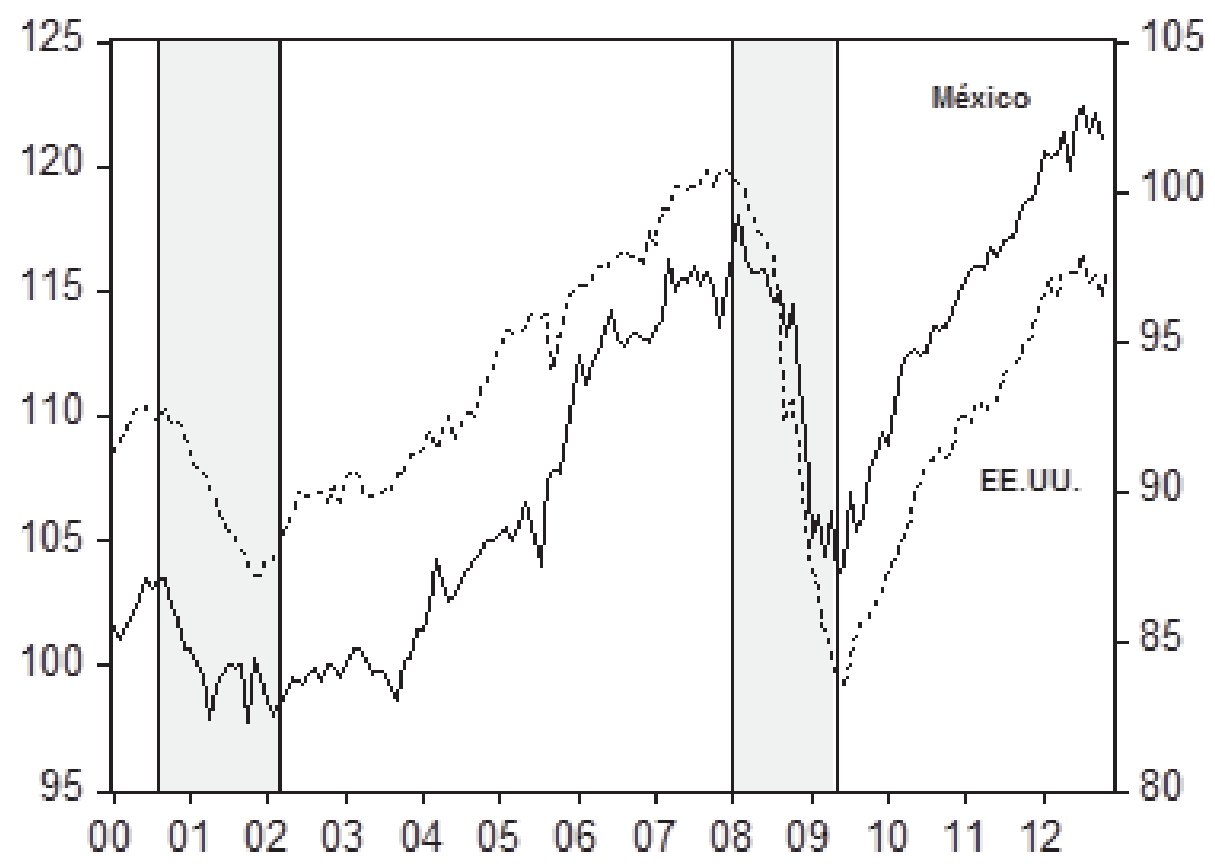

Fuente: Elaboración propia en base a datos de INEGI y de Federal Reserve Economic Data.

$$
\left.\mathrm{p} \mathrm{c}_{\text {mex }} \mathrm{c}_{\text {eeuu }}(\mathrm{i})=\left[\left(\frac{1}{\mathrm{~T}}-\mid \mathrm{i}\right)\right) \sum_{\mathrm{t}}\left(\mathrm{c}_{\text {mex }, \mathrm{t}}-\mathrm{c}_{\text {eeuu }}\right)\left(\mathrm{c}_{\text {mex }, \mathrm{t}-1}-\mathrm{c}_{\text {mex }}\right)\right] / \sigma_{\text {eеu }} \sigma_{\text {mex }}
$$

donde $\mathrm{p} \mathrm{c}_{\text {mex }} \mathrm{c}_{\text {eeuu }}$ (i) representa la correlación cruzada contemporánea si $\mathrm{i}=$ 0 , rezagada si $\mathrm{i}>0$, y adelantada si $\mathrm{i}<0$ entre $\mathrm{c}_{\text {mex }}$ y $_{\text {eeuu }}$ que representan el ciclo de México o sus sectores y/o regiones y el ciclo de EE. UU. respectivamente.

Así, al estimar la correlación cruzada contemporánea entre las tasas de crecimiento del PIв anual real de México y Estados Unidos para 19932012, resulta en un coeficiente de 0.65; pero si se calcula para 2000-2012, la correlación sube a 0.87 , pues como claramente se observa en la figura 3 , dicha asociación es más marcada en los últimos años, revelando que las recesiones de Estados Unidos de 2001 y 2009 influyeron en las de México en esos mismos años. 
Mientras que a escala regional dicha influencia se ha incrementado con el tiempo. Así, Cuevas et al. (2003) señalan a los estados del norte como los más vinculados al ciclo de Estados Unidos; Mejía y Campos (2011) y Mejía (2011) consideran que lo son, además de los estados del norte, los estados del centro del país; y Delajara (2011b, p. 22) incluso establece un orden de precedencia que va de una mayor vinculación a una menor: norte, centro, centro norte y sur, respectivamente.

Para examinar la evidencia regional de la recesión de 2009 y la expansión de 2010-2012 en el siguiente apartado, es pertinente considerar - además de la vinculación de las entidades federativas con el ciclo de EE. UU.- que sus expresiones serán diferentes en atención al perfil sectorial de las entidades federativas y al predominio de los diversos canales mediante los que la recesión y subsecuente expansión estadunidense se trasmitió a México y sus entidades federativas.

Mientras el canal de transmisión exportador manufacturero (especialmente las automotrices y de equipos eléctricos y electrónicos) parece la

Figura 3. Tasa de crecimiento anual del pib real de de México y EE.UU.

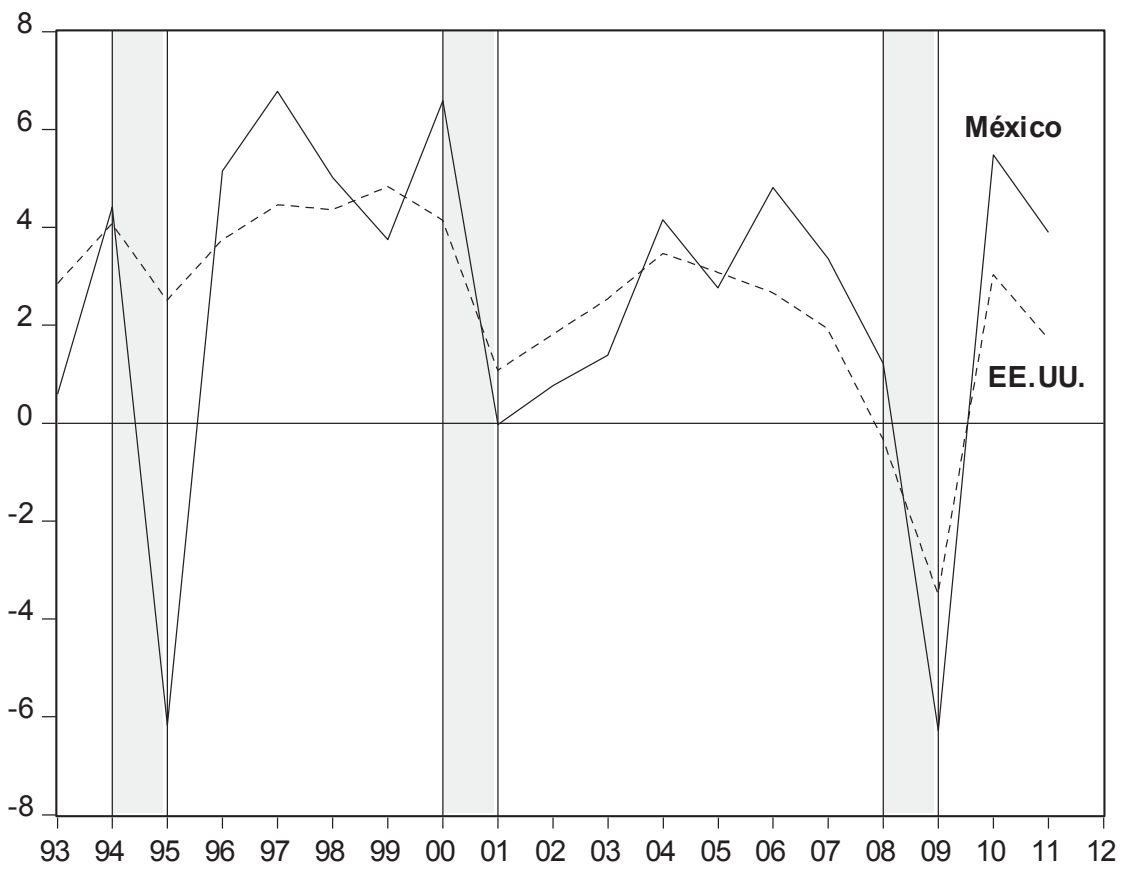

Fuente: Elaboración propia en base a datos de INEgi y de Federal Reserve Economic Data. 
principal vía por la que la fase del ciclo de Estados Unidos se sincroniza con la fase mexicana, en la recesión de 2009 y la expansión que le sigue, hay también otros canales de transmisión como los que se señalan en el cuadro 1. Así, en 2009 caen las exportaciones petroleras, los ingresos por turismo, los ingresos por remesas familiares y los ingresos por inversión extranjera directa. Mientras que en 2010-2012 dichos rubros se recuperan claramente, a excepción de las exportaciones petroleras, las remesas y la inversión extranjera directa en 2012.

\section{Cuadro 1. Ingreso de divisas en la Balanza de Pagos de México}

\begin{tabular}{|l|c|c|c|c|}
\hline Rubros de la Balanza de Pagos & 2009 & 2010 & 2011 \\
\hline \multicolumn{5}{|c|}{ Total de exportaciones manufactureras } \\
\hline En millones de dólares & 189698.4 & 245745.3 & 278617.1 & 301992.7 \\
\hline Tasa de crecimiento anual \% & -17.83736772 & 29.54526765 & 13.37636976 & 8.389865518 \\
\hline \multicolumn{5}{|c|}{ Exportaciones. Industria automotriz } \\
\hline En millones de dólares & 42373.1 & 64947.9 & 79176.5 & 88377.2 \\
\hline Tasa de crecimiento anual \% & -23.90 & 53.28 & 21.91 & 11.62 \\
\hline \multicolumn{5}{|c|}{ Exportaciones, equipos y aparatos eléctricos y electrónicos } \\
\hline En millones de dólares & 56932.6 & 67089.2 & 65325.9 & 68818 \\
\hline Tasa de crecimiento anual \% & -18.77 & 17.84 & -2.63 & 5.35 \\
\hline \multicolumn{5}{|c|}{ Exportaciones petroleras } \\
\hline En millones de dólares & 30831.3 & 41693.4 & 56385.1 & 53078.5 \\
\hline Tasa de crecimiento anual \% & -39.11 & 35.23 & 35.24 & -5.86 \\
\hline \multicolumn{5}{|c|}{ Ingresos por turismo } \\
\hline En millones de dólares & 9221 & 9990.8 & 10006.39 & 10712.2 \\
\hline Tasa de crecimiento anual \% & -14.75 & 8.35 & 0.16 & 7.05 \\
\hline \multicolumn{7}{|c|}{ Ingresos por remesas } \\
\hline En millones de dólares & 21306.3 & 21303.9 & 22803 & 22445.8 \\
\hline Tasa de crecimiento anual \% & -15.27 & -0.01 & 7.04 & -1.57 \\
\hline \multicolumn{7}{|c|}{ Ingresos por Inversión Extranjera Directa } & -41.13 \\
\hline En millones de dólares & 16560.5 & 21372.4 & 21503.7 & 0.61 \\
\hline Tasa de crecimiento anual \% & -40.54 & 29.06 & 2659.4 \\
\hline
\end{tabular}

Fuente: Elaborado con base en Banco de México, 2012, pp. 115-117. 


\section{Recesión 2009 y expansión 2010-2012 en las entidades federativas de México}

Ahora bien, para el análisis cíclico regional en México, paulatinamente se ha ido contando con más y mejores datos a escala regional:

- Producto Interno Bruto Estatal (PIBE) elaborado por el Intituto Nacional de Estadística y Geografía (INEGI), desagregado en nueve grandes divisiones y nueve divisiones de la industria manufacturera de 1993 a 2006 a precios de 1993, y PIB y PIBE (desagregado en 28 actividades según la clasificación del Sistema de Clasificación Industrial de América del Norte [SCIAN]) de 2003 a 2012, a precios de 2008.

- Índice Trimestral de la Actividad Económica Estatal (ITAEE) elaborado por el INEGI, desagregado en tres sectores: Primario, Secundario y Terciario, con datos que inician en el primer trimestre de 2003.

- Índice Coincidente por Entidad Federativa (ICEF) mensual con base en indicadores de la producción manufacturera, el empleo formal y las ventas al menudeo, con datos que inician en enero de 1994 para 14 entidades federativas y que con cifras a partir de enero de 2003 alcanzan una cobertura total. ${ }^{7}$

- Índice Coincidente Regional (ICR) elaborado por el Banco de México, con base en indicadores de la producción manufacturera, el empleo formal, las ventas al menudeo y al mayoreo y la generación y consumo de electricidad, con cifras que inician en enero de 2003.

Aquí, para constatar la diversidad regional en que se manifiestan las fases del ciclo económico nacional, se usa la información de la tasas de

${ }^{7}$ En Erquizio (2002), se formula, calcula y utiliza por primera vez dicho índice coincidente para identificar los ciclos de Sonora; en Erquizio (2006b), se hace lo mismo para 6 entidades federativas, en Erquizio (2008) para 8, en Erquizio (2007b) para 12 y en Erquizio (2010b) para todas. Como en la actualidad el ICR sólo se reporta por regiones, el ICEF elaborado por los autores para las 32 entidades federativas en una nueva versión que incluye los mismos indicadores del ICR, permite un examen más detallado y puntual de los ciclos de las 32 entidades federativas de México, que va más allá del alcance de este artículo. 
crecimiento del PIB de las entidades federativas (TCPIBE), pues como se comprueba en el cuadro 2, la amplitud de las recesiones ordenadas de mayor a menor es similar para cada indicador utilizado.

Así, en el mapa incluido en la figura 4 se documenta que las entidades del sur fueron relativamente menos afectadas por la recesión de 2009, a excepción de Campeche y Quintana Roo; y que las entidades del norte, centro y centro-norte fueron relativamente más afectadas por la recesión de 2009, a excepción de Durango, Morelos, Querétaro y Zacatecas.

Y si se promedian las tasas de crecimiento observadas de los PIBE de las entidades federativas en 2010, 2011 y 2012, se obtiene el mapa de la figura 5, y se documenta que mayoritariamente son las entidades del norte, centro y centro-norte las que encabezan la expansión de la economía mexicana (excepto Chihuahua, Tamaulipas, Sinaloa, Durango y Nayarit); y que las entidades del sur son las que se recuperan más lentamente (excepto Quintana Roo).

A continuación se usa información anual del PIBE total y del PIBE sectorial para relacionar la diversidad cíclica — detectada en las figuras 4 y 5 - con una tipología de las entidades federativas que se basa en su perfil sectorial. ${ }^{8}$

Por tanto, en el cuadro 3 se presenta la propuesta de tipología de las entidades federativas y la amplitud o profundidad de las recesiones medida por la tasa de crecimiento del PIBE en 2009. Y se comprueba que las entidades federativas que fueron menos afectadas por la recesión de 2009 son las vinculadas al sector primario, con un sector agrícola y agroalimentario importante, como Zacatecas, Veracruz, Morelos, Oaxaca, Chiapas, Guerrero y Durango; turísticas como Yucatán; y petroleras como Tabasco.

Mientras que las entidades federativas que fueron mucho más afectadas en la recesión de 2009 son en su mayoría las vinculadas a la manufactura, como Coahuila, Chihuahua, Tamaulipas, Nuevo León, Puebla, Baja California, Guanajuato, Aguascalientes y San Luis Potosí.

Asimismo, en el cuadro 4 se presenta la propuesta de tipología de las entidades federativas y la magnitud de la expansión 2010-2012 medida por la tasa de crecimiento promedio del PIBE en dicho lapso. Y se comprueba que las entidades federativas que encabezan la expansión son las

${ }^{8}$ La tipología se desarrolla ampliamente en Erquizio (2010b, pp. 18-21). 


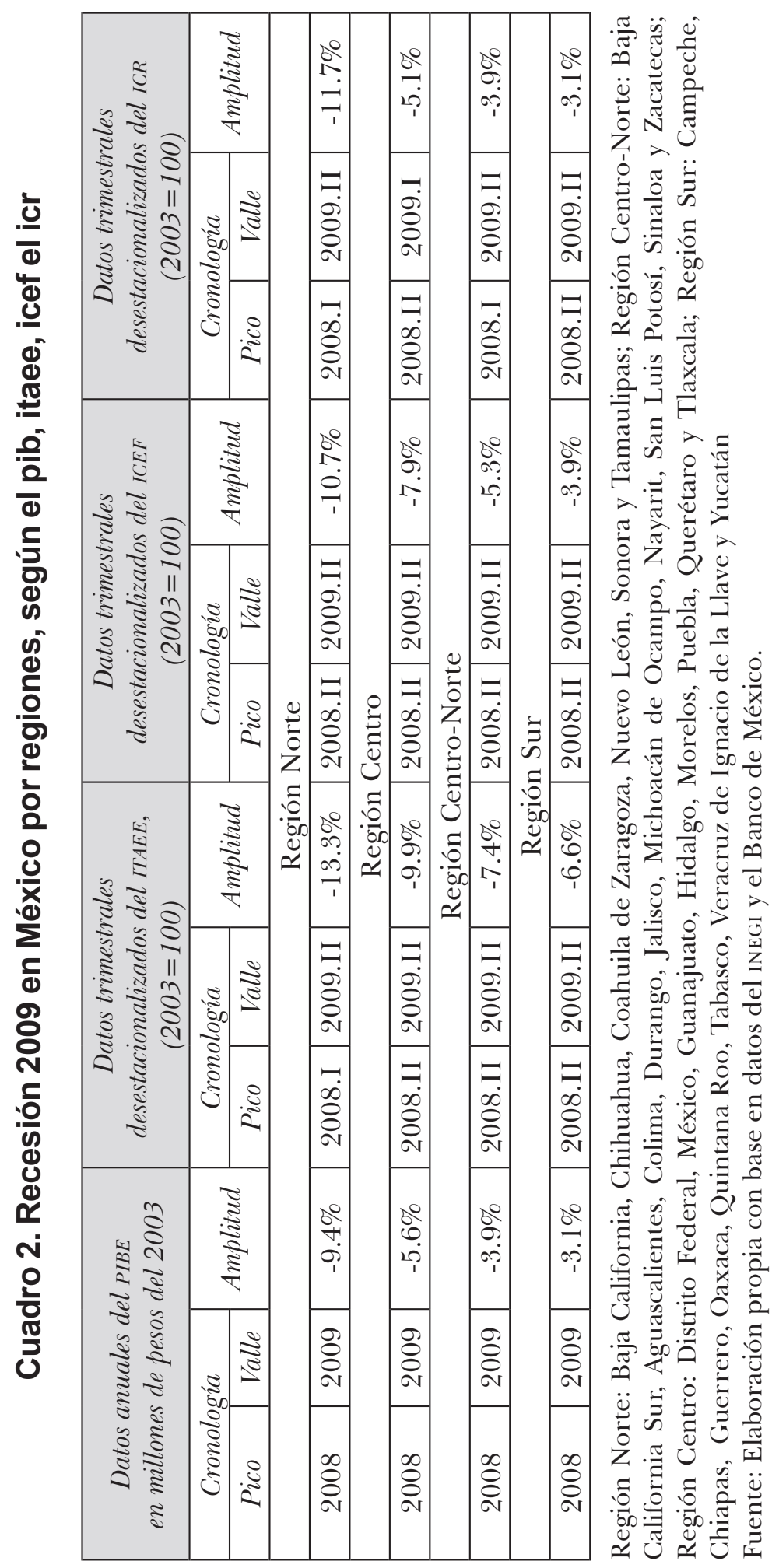


Figura 4. Recesión 2009 en las entidades federativas de México

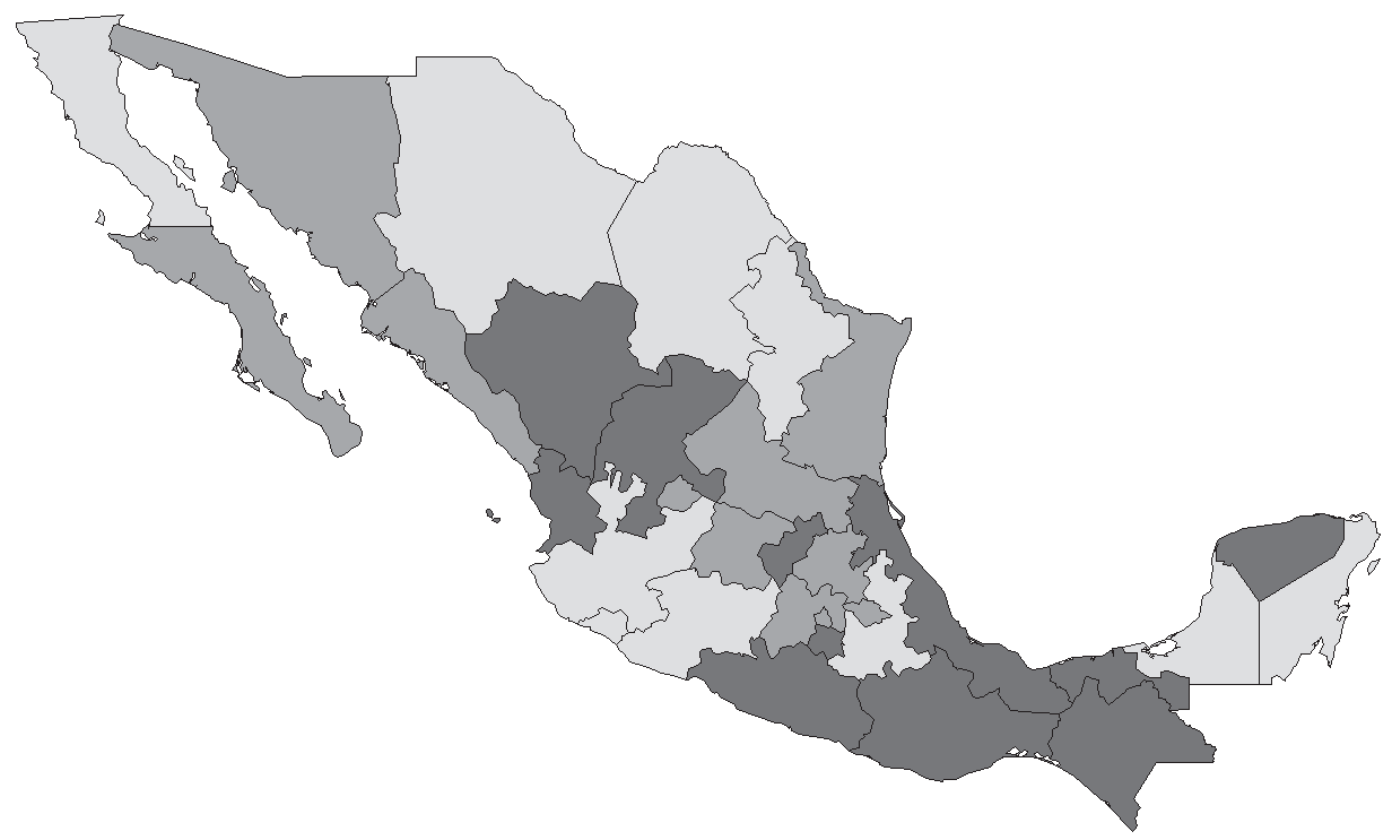

Nota: Los tres grupos de entidades federativas van de colores claros a oscuros o de una tasa menor de crecimiento del PIBE a una mayor, y son (-12.75 a -5.894), (-5.005 a -3.704), $(-3.691$ a 6.621$)$.

Fuente: Elaboración propia con datos del cuadro 3, mediante GEODA.

\section{Figura 5. Expansión 2010-2012 en las entidades federativas de México}

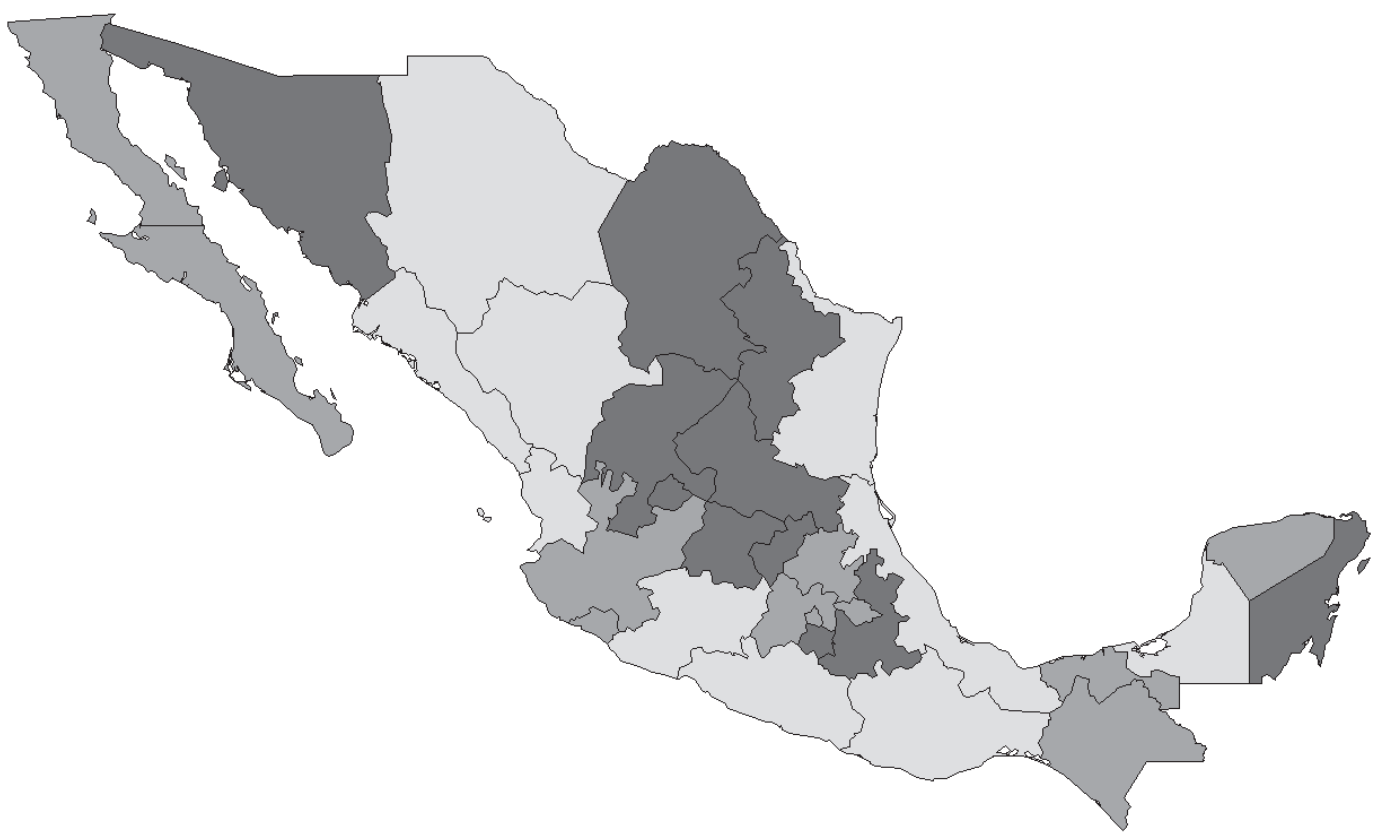

Nota: Los tres grupos de entidades federativas van de colores claros a oscuros o de una tasa menor de crecimiento promedio del PIB 2010-2012 a una mayor, y son (-2.862 a 3.568), (3.608 a 5.167), (5.183 a 9.493).

Fuente: Elaboración propia con datos del cuadro 4, mediante GEODA. 


\section{Cuadro 3. Tipología de las entidades federativas de México y recesión 2009}

\begin{tabular}{|c|c|c|c|}
\hline Entidad federativa & TСРIBE 2009 & Región & Tipología \\
\hline \multicolumn{4}{|c|}{ Entidades federativas mucho más afectadas en la recesión del 2009} \\
\hline Coahuila & -12.754 & Norte & Manufacturera-automotriz \\
\hline Campeche & -9.250 & Sur & Petrolera \\
\hline Baja California & -8.199 & Norte & Manufacturera-automotriz \\
\hline Chihuahua & -7.820 & Norte & Manufacturera-automotriz \\
\hline Nuevo león & -7.339 & Norte & Manufacturera \\
\hline Jalisco & -6.742 & Centro-norte & Agro-alimentaria \\
\hline Michoacan & -6.138 & Centro-norte & Agro-alimentaria \\
\hline Colima & -5.995 & Centro-norte & Minera \\
\hline Quintana Roo & -5.924 & Sur & Turística \\
\hline Puebla & -5.894 & Centro & $\begin{array}{l}\text { Manufacturera-automotriz y agro- } \\
\text { alimentaria }\end{array}$ \\
\hline \multicolumn{4}{|c|}{ Entidades federativas más afectadas en la recesión del 2009} \\
\hline Baja California Sur & -5.005 & Centro-norte & Turística \\
\hline Hidalgo & -4.984 & Centro & Agro-alimentaria \\
\hline Sinaloa & -4.660 & Centro-norte & Agro-alimentaria \\
\hline Guanajuato & -4.658 & Centro & Agro-alimentaria y manufacturera-automotriz \\
\hline Tamaulipas & -4.630 & Norte & Manufacturera \\
\hline Aguascalientes & -4.595 & Centro-norte & Agro-alimentaria y manufacturera-automotriz \\
\hline San Luis Potosí & -4.172 & Centro-norte & Manufacturera-automotriz y agro-alimentaria \\
\hline Distrito Federal & -3.945 & Centro & Servicios \\
\hline Tlaxcala & -3.871 & Centro & Agro-alimentaria \\
\hline México & -3.806 & Centro & Manufacturera-automotriz \\
\hline Sonora & -3.704 & Norte & $\begin{array}{l}\text { Manufacturera-automotriz y agro- } \\
\text { alimentaria }\end{array}$ \\
\hline \multicolumn{4}{|c|}{ Entidades federativas menos afectadas en la recesión del 2009} \\
\hline Nayarit & -3.691 & Centro-norte & Agro-alimentaria \\
\hline Durango & -3.068 & Centro-norte & Agro-alimentaria y minera \\
\hline Morelos & -2.728 & Centro & Agro-alimentaria \\
\hline Querétaro & -2.639 & Centro & Agro-alimentaria y manufacturera \\
\hline Yucatán & -2.122 & Sur & Turística \\
\hline Chiapas & -1.321 & Sur & Agrícola \\
\hline Oaxaca & -0.970 & Sur & Agro-alimentaria \\
\hline Guerrero & -0.764 & Sur & Agro-alimentaria \\
\hline Veracruz & -0.610 & Sur & Agro-alimentaria \\
\hline Tabasco & 3.843 & Sur & Petrolera \\
\hline Zacatecas & 6.621 & Centro-norte & Agro-alimentaria y minera \\
\hline
\end{tabular}

* Se mide así: [(Valor del indicador del ciclo en el valle final / Valor del indicador del ciclo en el pico inicial) -1$] * 100$.

Fuente: Elaboración propia con base en datos del INEGI. 
vinculadas al sector manufacturero en general y en particular al sector automotriz.

Es notable también que las entidades con una recuperación más lenta son mayoritariamente las que tiene un sector agroalimentario predominante y aquellas que como Tamaulipas y Chihuahua parecen ya sufrir los embates económicos del ambiente de violencia (Banamex-CiTI, 2012). Y las entidades que muestran las más bajas tasas de crecimiento en 2012 son Sinaloa (afectada por las heladas que se presentaron durante los primeros meses de 2011) y Campeche, en la que la disminución de extracción de petróleo por agotamiento de yacimientos ha generado una contracción recurrente del PIBE desde 2003, por lo que dicha entidad padece un colapso económico ya prolongado y no un ciclo económico.

\section{Diversidad recesiva regional y ecuación de ciclo regional}

En la figura 1, los ciclos nacionales se manifiestan en un contexto tendencial creciente. La explicación teórica de dicho movimiento y una forma de modelarlo matemáticamente a escala nacional, constituyó el aporte seminal de Frish $(1933)^{9}$ mediante la metáfora del rocking horse,${ }^{10}$ al distinguir que para modelar el ciclo económico era necesario resolver:

${ }^{9}$ Véase en Jarsulic (1993) una discusión del aporte de Frish. Allí también se señala la importancia de Slutsky (1937), quien usó los números aleatorios generados por la lotería rusa para producir series de tiempo; luego, con esos datos, construyó varios promedios móviles, y al graficarlos mostró su similitud con las series económicas cíclicas. Ello implicó que cualquier variable económica pudiera ser explicada por una ecuación lineal en diferencias de la forma: $\mathrm{X}_{\mathrm{t}}=\mathrm{a} \mathrm{X}_{\mathrm{t}-1}+\mathrm{e}_{\mathrm{t}}$ en el que $\mathrm{e}_{\mathrm{t}}$ es una variable aleatoria no serialmente correlacionada (Jarsulic, 1993, p. 347).

${ }^{10}$ Louca (2001, p. 29) señala que la idea original es de Wicksell: "La metáfora fue sugerida originalmente en una nota de pie de página por Wicksell y referida por Ackerman en su tesis doctoral. Probablemente ambas referencias habrían sido condenadas a la obscuridad, si Frisch no hubiera considerado a Wicksell el más grande economista y si no hubiera sido miembro del jurado de Ackerman en 1928. Él incorporó rápidamente la metáfora en su investigación y formuló un modelo de los ciclos trascendental inspirado en esta percepción”. 


\section{Cuadro 4. Tipología de las entidades federativas de México y expansión 2010-2012}

\begin{tabular}{|c|c|c|c|}
\hline Entidad federativa & $\begin{array}{c}\text { TCPIBE } \\
2010-2012\end{array}$ & Región & Tipología \\
\hline \multicolumn{4}{|c|}{ Entidades federativas que se expanden más rápido } \\
\hline Coahuila & 9.493 & Norte & Manufacturera-automotriz \\
\hline Nuevo León & 6.584 & Norte & Manufacturera \\
\hline Puebla & 6.530 & Centro & Manufacturera-automotriz y agro-alimentaria \\
\hline Sonora & 6.526 & Norte & Manufacturera-automotriz y agro-alimentaria \\
\hline Querétaro & 6.058 & Centro & Agro-alimentaria y manufacturera \\
\hline San Luís Potosí & 6.024 & Centro-norte & Manufacturera-automotriz y agro-alimentaria \\
\hline Guanajuato & 5.830 & Centro & Agro-alimentaria y manufacturera-automotriz \\
\hline Zacatecas & 5.735 & Centro-norte & Agro-alimentaria y minera \\
\hline Morelos & 5.707 & Centro & Agro-alimentaria \\
\hline Quintana Roo & 5.414 & Sur & Turística \\
\hline Aguascalientes & 5.183 & Centro-norte & Agro-alimentaria y manufacturera-automotriz \\
\hline \multicolumn{4}{|c|}{ Entidades federativas que se expanden menos rápido } \\
\hline Colima & 5.167 & Centro-norte & Minera \\
\hline México & 4.912 & Centro & Manufacturera-automotriz \\
\hline Jalisco & 4.741 & Centro-norte & Agro-alimentaria \\
\hline Tlaxcala & 4.547 & Centro & Agro-alimentaria \\
\hline Hidalgo & 4.521 & Centro & Agro-alimentaria \\
\hline Chiapas & 4.511 & Sur & Agrícola \\
\hline Tabasco & 4.366 & Sur & Petrolera \\
\hline Distrito Federal & 4.190 & Centro & Servicios \\
\hline Baja California Sur & 3.958 & Centro-norte & Turística \\
\hline Yucatán & 3.682 & Sur & Turística \\
\hline Baja California & 3.608 & Norte & Manufacturera-automotriz \\
\hline \multicolumn{4}{|c|}{ Entidades federativas que se expanden lentamente } \\
\hline Chihuahua & 3.568 & Norte & Manufacturera-automotriz \\
\hline Durango & 3.498 & Centro-norte & Agro-alimentaria y minera \\
\hline Michoacán & 3.470 & Centro-norte & Agro-alimentaria \\
\hline Veracruz & 3.435 & Sur & Agro-alimentaria \\
\hline Oaxaca & 3.241 & Sur & Agro-alimentaria \\
\hline Nayarit & 2.611 & Centro-norte & Agro-alimentaria \\
\hline Tamaulipas & 2.505 & Norte & Manufacturera \\
\hline Guerrero & 2.418 & Sur & Agro-alimentaria \\
\hline Sinaloa & 2.346 & Centro-norte & Agro-alimentaria \\
\hline Campeche & -2.862 & Sur & Petrolera \\
\hline
\end{tabular}

Fuente: Elaboración propia con base en datos del INEGI. 
- El problema del mecanismo de propagación, es decir, de las relaciones internas entre las variables cuando el sistema está en equilibrio.

- El problema del mecanismo de impulso que rompe el equilibrio y lo mueve en una trayectoria cíclica que es amplificada y/o dibujada por la naturaleza de las relaciones elegidas como representativas del funcionamiento interno del sistema económico, o mecanismo de propagación.

Es decir, de acuerdo con la forma y longitud del balancín (mecanismo de propagación) y la fuerza, secuencia o periodicidad del mecanismo de impulso (características del martillo que golpea el balancín que representa la economía), se describirá una secuencia de movimientos que es el símil mecánico del movimiento cíclico de la economía. Lo que permite intuir que dado un impulso, la economía se moverá describiendo una trayectoria resultado de la magnitud del mecanismo de impulso y de la forma del mecanismo de propagación.

Quedaba así vinculado lo estructural (o lo permanente) que entra en movimiento (dinámica económica) cuando una fuerza exógena saca del equilibrio o reposo al sistema económico.

¿Pero cómo pensar la relación estructura y ciclos a escala regional? Para ello, el aporte de Wesley Clair Mitchell ${ }^{11}$ es fundamental y es lo que aquí se denomina como la hipótesis de los ciclos económicos. Por lo que si bien los ciclos son un fenómeno de alcance nacional, puesto que se trata de un movimiento simultáneo al ascenso y al descenso de un amplio conjunto de variables económicas, es posible clasificar éstas en sus dimensiones sectorial y regional. Lo que permite caracterizar una economía nacional

${ }^{11}$ Nació en Rushville, Illinois, en 1874. Fue uno de los primeros investigadores que utilizó la técnica estadística para el estudio de los ciclos económicos. Estudió en la Universidad de Chicago y fue alumno de Thorstein Veblen y John Dewey. Enseñó en la New School For Social Research, colaboró en la fundación de la National Bureau of Economic Research (NBER) y se convirtió en su director, continuó su labor académica en la Universidad de Columbia hasta su retirada en 1944. Entre sus libros destacan Business cycles (1913), The making and using of index numbers (1915), Business cycles: The problem and its setting (1927), la obra coproducida con Artur Burns, Measuring business cycles, publicada en 1946, dos años antes de su muerte en Nueva York, y What happens during business cycles (1951). Westley Clair Mitchell. (Diciembre, 2012). En Wikipedia. Recuperado de $<$ http://es.wikipedia.org/wiki/Wesley_Clair_Mitchell > . 
y sus economías regionales, considerando su comportamiento sectorial en varios ciclos económicos. Y conjeturar que por ejemplo las recesiones en los ciclos de las economías regionales en las que predominen los sectores económicos, que en el agregado nacional tiene recesiones más marcadas, mostrarán también dicha característica. Por lo que aparece también aquí la idea de que la estructura determina la dinámica.

Dado el carácter simultáneo del movimiento cíclico de las actividades económicas, cada una de éstas tendrá sus ciclos específicos, por lo que al examinarlas se podrá definir el cuarto rasgo de las recesiones:

- Difusión, o qué tan profuso es el movimiento de descenso de los ciclos específicos en proporción al total de ciclos específicos examinados.

$\mathrm{Y}$ es que si bien los ciclos económicos pueden ser identificados con medidas agregadas como el PIB, en realidad en el enfoque de los ciclos clásicos de Mitchell, son más que el movimiento al ascenso y al descenso de dicha variable, pues los ciclos son un movimiento multidimensional que permite medir la magnitud de su difusión, lo cual puede entenderse en dos sentidos.

Por una parte, si se examina un ciclo en particular, es decir, sincrónicamente, la situación límite de un ciclo es que éste se exprese en todas las dimensiones de la esfera económica. Por lo que, por ejemplo, si en una recesión desciende la producción en todos sus sectores, el Índice de Difusión Sincrónico Sectorial (IDss) alcanzaría el valor de 100\%. Si ello ocurriera en todas las regiones, el Índice de Difusión Sincrónico Regional (IDSR) alcanzaría el valor de $100 \%$. Y si a modo de "tormenta perfecta" la economía estuviera en recesión en todos los sectores y en todas las regiones, el Índice de Difusión Sincrónico Sectorial-Regional (IDSSR) alcanzaría el valor de $100 \%$. Es obvio que en la realidad ninguna recesión de un ciclo observado es así: algunos se acercarán a dichos límites, será el caso de las recesiones más graves; otros estarán más lejos, y será el caso de las recesiones más leves.

Pero también hay otra forma de calcular el índice de difusión, y es comparar el comportamiento cíclico de la producción sectorial nacional en varias recesiones, es decir, diacrónicamente. Así, existirán sectores productivos que descienden en todas las recesiones examinadas, con un Índice 
de Difusión Diacrónico Sectorial (IDDS) de 100\%, y otros en los que no ocurra así. Por lo que es una característica o "hecho estilizado" de los ciclos nacionales que hay sectores que caen en todas las recesiones, y en el extremo otros sectores que no lo hacen. Así, también existirán regiones que descienden en todas las recesiones examinadas, con un Índice de Difusión Diacrónico Regional (IDDR) de 100\%, y otras en las que no ocurra así.

Para ilustrar el cálculo de los índices mencionados es útil definir para una economía nacional, o del mismo modo para una economía regional, una matriz de $n$ sectores de actividad económica por $m$ recesiones. Cada elemento de dicha matriz es el indicador recesivo (IR) del sector $i$ en la recesión $j\left(\operatorname{IR}_{\mathrm{i}}^{\mathrm{j}}\right)$, que es 0 si en el sector $i$ en la recesión $j$ el sector $i$ mostró un tasa de variación positiva; y es 1 si en el sector $i$ en la recesión $j$ el sector $i$ mostró un tasa de variación negativa (o sea, estuvo en recesión).

De esta manera, en el cuadro 5 se muestra como ejemplo una matriz de $5 \times 5$, en la que se usa las fórmulas para los sectores del 1 al 5 en 5 recesiones, de tal suerte que por ejemplo:

- Índice de Difusión Sincrónico Sectorial de la recesión 1 es $\operatorname{IDSs}^{1}=$ $\left[\left(\sum_{1}{ }^{\mathrm{n}} I \mathrm{R}_{\mathrm{i}}^{\mathrm{j}}\right) / \mathrm{n}\right]^{*} 100$, y así sucesivamente hasta la recesión 5 .

- Índice de Difusión Diacrónico Sectorial del sector 1 es $\operatorname{IDDs}_{1}=$ $\left[\left(\sum_{1}{ }^{\mathrm{m}} \mathrm{IR}_{\mathrm{i}}^{\mathrm{j}}\right) / \mathrm{m}\right]^{*} 100$, y así sucesivamente hasta el sector 5 .

Con lo que se puede:

- Comparar las recesiones de una economía nacional o en su caso de una economía regional por la difusión sectorial de dicho fenómeno, distinguiendo aquellas recesiones más graves (con Índice de Difusión Sincrónico Sectorial más alto) de otras recesiones menos graves (con un Índice de Difusión Sincrónico Sectorial más bajo).

- Caracterizar una economía nacional o en su caso una economía regional por la naturaleza de su perfil recesivo a lo largo de varias recesiones, distinguiendo aquellos sectores más recesivos (con Índice de Difusión Diacrónico Sectorial más alto) de otros sectores menos recesivos (con un Índice de Difusión Diacrónico más bajo). Y que este rasgo de las recesiones de los ciclos nacionales, o en su 
caso los regionales, es estructural en la medida que representa una regularidad cíclica observada en varias recesiones.

Se puede ilustrar el uso de la matriz de indicadores recesivos para la economía mexicana en las recesiones de 1982, 1983, 1986, 1995 y 2009 (cuadro 6). Comprobando así que los sectores más recesivos de la economía nacional son los vinculados a las divisiones que integran la gran división de la industria manufacturera. Por lo que se puede conjeturar que las entidades federativas en que dichas actividades predominen relativamente, serían las más recesivas, como ya se comprobó en el apartado anterior.

Así como la matriz de Indicadores Recesivos $\operatorname{IR}_{\mathrm{i}}^{\mathrm{j}}$ se puede construir para la economía nacional, también es posible elaborarla para cada una de las regiones del país, y por tanto, se puede establecer la medida en que el perfil de recesión nacional-sectorial se replica a nivel regional-sectorial. En este sentido, hay dos posibilidades extremas: la Matriz de Indicadores de Recesión IRij de la economía nacional coincide celda a celda con, por ejemplo, la Matriz de Indicadores de Recesión IRij de una economía regional $A$, o no coincide en absoluto. En el primer caso será $100 \%$ similar y en el segundo caso será $0 \%$ similar, y en otros casos adoptará valores intermedios de mayor o menor semejanza relativa.

Cuadro 5. Matriz de Indicadores recesivos $\mathbf{I R}_{\mathrm{i}}^{\mathrm{j}}$ of $n$ sectores económicos y $m$ recesiones

\begin{tabular}{|c|c|c|c|c|c|c|}
\hline \multirow[b]{2}{*}{$n$ sectores económicos } & \multicolumn{5}{|c|}{$m$ recesiones } & \multirow[b]{2}{*}{$I D D S=\left[\left(\sum_{l}^{m} I R_{i}^{j}\right) / m\right] * 100$} \\
\hline & $\begin{array}{c}\text { Recesión } \\
1\end{array}$ & $\begin{array}{c}\text { Recesión } \\
2\end{array}$ & $\begin{array}{c}\text { Recesión } \\
3\end{array}$ & $\begin{array}{c}\text { Recesión } \\
4\end{array}$ & \begin{tabular}{|c|} 
Recesión \\
5
\end{tabular} & \\
\hline Sector 1 & 1 & 0 & 1 & 1 & 0 & $\begin{array}{l}\text { IDDS }_{1} \\
=(3 / 5) * 100=60 \%\end{array}$ \\
\hline Sector 2 & 1 & 0 & 1 & 1 & 1 & $\mathrm{IDDS}_{2}=80 \%$ \\
\hline Sector 3 & 0 & 1 & 0 & 1 & 1 & $\mathrm{IDDS}_{3}=60 \%$ \\
\hline Sector 4 & 1 & 1 & 1 & 1 & 1 & $\mathrm{IDDS}_{4}=100 \%$ \\
\hline Sector 5 & 1 & 1 & 1 & 1 & 0 & $\mathrm{IDDS}_{5}=80 \%$ \\
\hline $\operatorname{IDDS}=\left[\left(\Sigma_{1}{ }^{\mathrm{n}} \mathrm{IR}_{\mathrm{i}}^{\mathrm{j}}\right) / \mathrm{n}\right] * 100$ & $\begin{array}{l}\text { IDDS }^{1} \\
(4 / 5)^{*} 100=80 \%\end{array}$ & $\begin{array}{l}\text { IDDS }^{2} \\
60 \%\end{array}$ & $\begin{array}{l}\text { IDDS }^{3} \\
60 \%\end{array}$ & $\begin{array}{l}\text { IDDS }^{4} \\
100 \%\end{array}$ & $\begin{array}{l}\mathrm{IDDS}^{5} \\
60 \%\end{array}$ & \\
\hline
\end{tabular}

Fuente: Elaboración propia. 


\section{Cuadro 6. Matriz de Indicadores recesivos $I R_{i}^{j}$ de la economía mexicana de 17 sectores económicos en 6 recesiones}

\begin{tabular}{|l|c|c|c|c|c|c|c|}
\hline \multirow{2}{*}{17 sectores de actividad económica } & \multicolumn{5}{|c|}{6 recesiones } & \multirow{2}{*}{ IDDS } \\
\cline { 2 - 9 } & 1982 & 1983 & 1986 & 1995 & 2001 & 2009 & \\
\hline GD1 Agropecuario, silvicultura y pesca & 1 & 0 & 1 & 0 & 0 & 1 & 50 \\
\hline GD2 Minería & 0 & 1 & 1 & 1 & 0 & 1 & 66.7 \\
\hline DI Productos alimenticios, bebidas y tabaco & 0 & 1 & 1 & 0 & 0 & 1 & 50 \\
\hline DII Textiles, prendas de vestir e industria del cuero & 1 & 1 & 1 & 1 & 1 & 1 & 100 \\
\hline DIII Industria de la madera y productos de madera & 1 & 1 & 1 & 1 & 1 & 1 & 100 \\
\hline DIV Papel, productos de papel, imprentas y editoriales & 0 & 1 & 1 & 1 & 1 & 1 & 83.3 \\
\hline DV Sustancias químicas, derivados del petróleo, caucho & 0 & 1 & 1 & 1 & 1 & 1 & 83.3 \\
\hline $\begin{array}{l}\text { DVI Prod. minerales, no metálicos (excepto } \\
\text { petróleo y carbón) }\end{array}$ & 1 & 1 & 1 & 1 & 1 & 1 & 100 \\
\hline DVII Industrias metálicas básicas & 1 & 1 & 1 & 0 & 1 & 1 & 83.3 \\
\hline DVIII Productos metálicos, maquinaria y equipo & 1 & 1 & 1 & 1 & 1 & 1 & 100 \\
\hline DIX Otras industrias manufactureras & 1 & 1 & 1 & 1 & 1 & 1 & 100 \\
\hline GD4 Construcción & 1 & 1 & 1 & 1 & 1 & 1 & 100 \\
\hline GD5 Electricidad, gas y agua & 0 & 0 & 0 & 0 & 0 & 0 & 0 \\
\hline DD6 Comercio, restaurantes y hoteles & 1 & 1 & 1 & 1 & 1 & 1 & 100 \\
\hline GD7 Transporte, almacenamiento y comunicación & 1 & 1 & 1 & 1 & 0 & 1 & 83.3 \\
\hline GD8 Servicios financieros, seguros y b. inmuebles & 0 & 0 & 0 & 1 & 0 & 1 & 33.3 \\
\hline GD9 Servicios comunales, sociales y personales & 0 & 0 & 1 & 1 & 1 & 1 & 66.7 \\
\hline IDSS & 58.8 & 76.5 & 88.2 & 76.5 & 64.7 & 94.1 & \\
\hline Tasa de crecimiento del pIB nacional & -0.6 & -4.1 & -3.7 & -6.1 & -0.03 & -6.0 & \\
\hline
\end{tabular}

Fuente: Elaboración propia con base en datos del INEGI.

Índice de Semejanza Recesiva Regional $=(\#$ de recesiones sectorialregional que coinciden con la respectiva sectorial-nacional en los años de recesión nacional / \# de recesiones sectorial-nacionales)*100.

Se puede calcular dicho índice comparando la matriz de indicadores recesivos de cada entidad federativa con la matriz nacional y obtener los resultados que se muestran en el cuadro 7 , y se puede conjeturar que las entidades federativas con un perfil recesivo más semejante al nacional, serían también las más recesivas.

Por lo que al tratar el asunto de las causas estructurales de las manifestaciones regionales diferenciadas de los ciclos nacionales, se cuenta con dos nuevos instrumentos muy importantes —que aquí se aportan a la 
literatura de los ciclos económicos clásicos- - y que son aplicables al análisis regional. Se trata de:

- Índices de difusión sincrónico y diacrónico, que permiten revelar "hechos estilizados" de los ciclos sectoriales nacionales que, contrastados con los perfiles sectoriales regionales, posibilitarán postular que en las regiones en las que predominen los sectores que en lo nacional son lo más recesivos, serán también las regiones en que los ciclos nacionales se expresen con efectos recesivos más marcados.

- Índices de semejanza recesiva, que permiten comparar la incidencia sectorial de las recesiones en una región con lo que ocurre a escala nacional, y que permitirán aducir que las regiones más semejantes a la economía nacional desde el punto de vista recesivo, serán también las que presenten efectos recesivos más marcados.

Respecto del mecanismo de impulso o causa exógena, como se vio en el primer apartado, los ciclos de las economías de México y Estados Unidos parecen cada vez más vinculados desde que se implementó el Tratado de Libre Comercio para América del Norte (TLCAN) y tanto la recesión de 2001 como la de 2009 estuvieron fuertemente asociadas al comportamiento del sector exportador y por tanto al entorno internacional; otra causa de la diferenciación de las recesiones regionales sería el índice de correlación entre el crecimiento de cada entidad federativa y el crecimiento de Estados Unidos en el lapso 1994-2006 o una medida más elaborada como el coeficiente de elasticidad reportado por el Banco de México (2011, p. 4) y por Delajara (2011b, p. 23).

Establecida la importancia del papel del mecanismo de propagación y del mecanismo de impulso, es necesario añadir un mecanismo contra cíclico como la acción del gobierno mediante su mayor activismo fiscal (representado por la proporción del gasto público devengado respecto del PIB por entidad federativa), pues éste, como se observa en la figura 6, tuvo un comportamiento contracíclico en la Gran Recesión de 2009. ${ }^{12}$

${ }^{12}$ Varios autores han revelado el carácter contracíclico, aunque insuficiente, de la política fiscal a escala nacional: Chávez, Rodríguez y Fonseca (2010), Palacios (2009), y Villagómez y Navarro (2010). En Erquizio y Ramírez (2012) se sustenta que ello también ocurrió a escala regional y que sus efectos fueron previsiblemente mayores 


\section{Cuadro 7. Índice de Semejanza Recesiva Regional}

\begin{tabular}{|c|c|c|c|c|c|c|}
\hline \multirow{3}{*}{$\begin{array}{l}\text { Entidades } \\
\text { federativas }\end{array}$} & \multicolumn{6}{|c|}{ Recesiones } \\
\hline & \multicolumn{2}{|c|}{1995} & \multicolumn{2}{|c|}{2001} & \multicolumn{2}{|c|}{2009} \\
\hline & $\begin{array}{l}\text { Número de } \\
\text { recesiones }\end{array}$ & $\begin{array}{l}\text { Indice de } \\
\text { semejanza } \\
\text { recesiva }\end{array}$ & $\begin{array}{l}\text { Número de } \\
\text { recesiones }\end{array}$ & $\begin{array}{c}\text { Indice de } \\
\text { semejanza } \\
\text { recesiva }\end{array}$ & $\begin{array}{l}\text { Número de } \\
\text { recesiones }\end{array}$ & $\begin{array}{l}\text { Índice de } \\
\text { semejanza } \\
\text { recesiva }\end{array}$ \\
\hline Aguascalientes & 10 & 76.9 & 5 & 45.5 & 13 & 46.4 \\
\hline Baja California & 8 & 61.5 & 6 & 54.5 & 20 & 71.4 \\
\hline Baja California Sur & 8 & 61.5 & 3 & 27.3 & 16 & 57.1 \\
\hline Campeche & 10 & 76.9 & 6 & 54.5 & 15 & 53.6 \\
\hline Coahuila & 9 & 69.2 & 10 & 90.9 & 18 & 64.3 \\
\hline Colima & 12 & 92.3 & 9 & 81.8 & 16 & 57.1 \\
\hline Chiapas & 8 & 61.5 & 6 & 54.5 & 14 & 50.0 \\
\hline Chihuahua & 6 & 46.2 & 8 & 72.7 & 20 & 71.4 \\
\hline Distrito Federal & 12 & 92.3 & 10 & 90.9 & 20 & 71.4 \\
\hline Durango & 9 & 69.2 & 7 & 63.6 & 15 & 53.6 \\
\hline Guanajuato & 9 & 69.2 & 7 & 63.6 & 16 & 57.1 \\
\hline Guerrero & 9 & 69.2 & 9 & 81.8 & 17 & 60.7 \\
\hline Hidalgo & 8 & 61.5 & 8 & 72.7 & 20 & 71.4 \\
\hline Jalisco & 12 & 92.3 & 8 & 72.7 & 22 & 78.6 \\
\hline México & 12 & 92.3 & 7 & 63.6 & 15 & 53.6 \\
\hline Michoacán & 9 & 69.2 & 8 & 72.7 & 16 & 57.1 \\
\hline Morelos & 12 & 92.3 & 4 & 36.4 & 16 & 57.1 \\
\hline Nayarit & 11 & 84.6 & 6 & 54.5 & 15 & 53.6 \\
\hline Nuevo León & 10 & 76.9 & 8 & 72.7 & 18 & 64.3 \\
\hline Oaxaca & 8 & 61.5 & 6 & 54.5 & 13 & 46.4 \\
\hline Puebla & 12 & 92.3 & 7 & 63.6 & 19 & 67.9 \\
\hline Querétaro & 10 & 76.9 & 9 & 81.8 & 16 & 57.1 \\
\hline Quintana Roo & 10 & 76.9 & 2 & 18.2 & 14 & 50.0 \\
\hline San Luís Potosí & 9 & 69.2 & 8 & 72.7 & 18 & 64.3 \\
\hline Sinaloa & 10 & 76.9 & 5 & 45.5 & 16 & 57.1 \\
\hline Sonora & 6 & 46.2 & 5 & 45.5 & 16 & 57.1 \\
\hline Tabasco & 10 & 76.9 & 6 & 54.5 & 16 & 57.1 \\
\hline Tamaulipas & 5 & 38.5 & 7 & 63.6 & 18 & 64.3 \\
\hline Tlaxcala & 10 & 76.9 & 5 & 45.5 & 16 & 57.1 \\
\hline Veracruz & 10 & 76.9 & 9 & 81.8 & 16 & 57.1 \\
\hline Yucatán & 11 & 84.6 & 6 & 54.5 & 15 & 53.6 \\
\hline Zacatecas & 10 & 76.9 & 5 & 45.5 & 10 & 35.7 \\
\hline
\end{tabular}

Fuente: Elaboración propia con base en datos del INEGI. 
Figura 6. Gasto público como proporción del pib por regiones

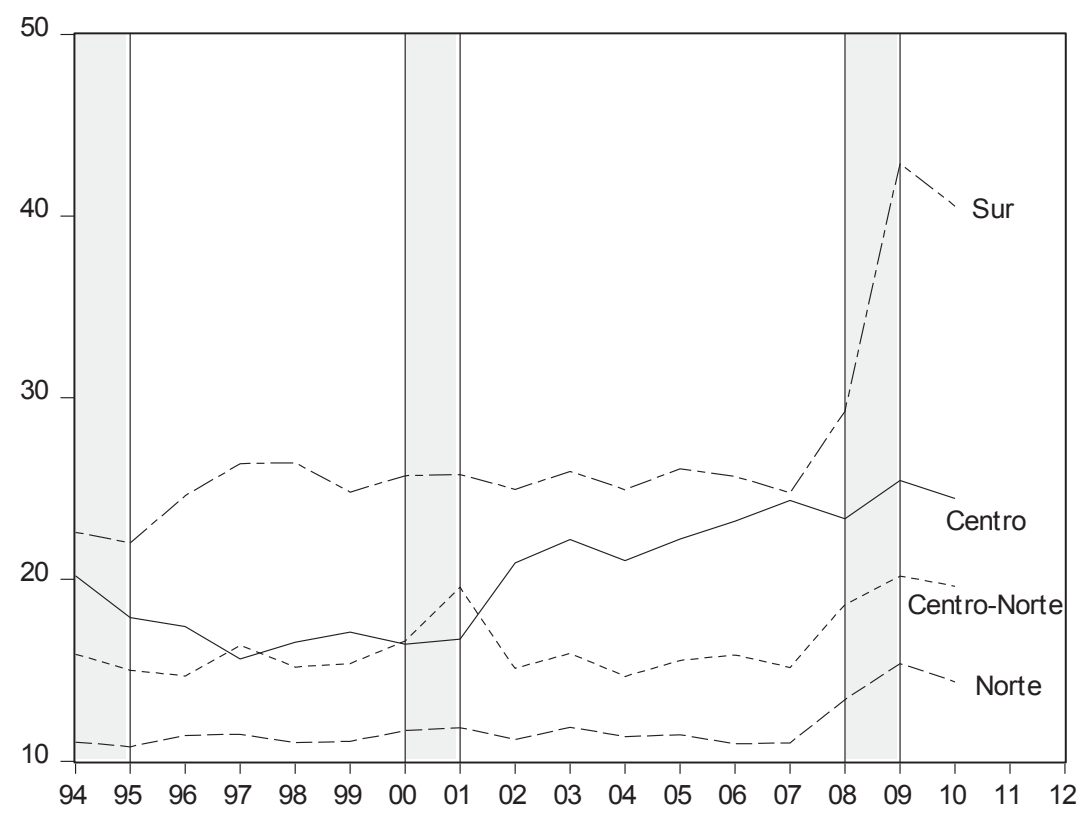

Fuente: Elaboración propia con datos del InEgi y Presidencia de la República, 2011.

Y mediante regresiones de corte transversal, se estima la relevancia estadística de los factores exógenos (mecanismo de impulso), los factores endógenos (mecanismo de propagación) y del gasto público (mecanismo contra cíclico) como factores explicativos de la diversidad recesiva regional en 2009. Y de acuerdo con los diagramas de dispersión consignados en la figura 7 y las regresiones reportadas en el cuadro 8, se comprueba que las entidades federativas con una: ${ }^{13}$

en las entidades federativas más pobres, en las que el gasto público respecto del PIBE es mayor, dada la debilidad de la actividad privada en dichas entidades. Otra vertiente del análisis de los ingresos y el gasto público a nivel federal y estatal es la del ciclo político económico y la del ciclo político presupuestal, como en Gámez e Ibarra-Yuñez (2009) y Ramírez y Erquizio (2012) desde una perspectiva regional, y Reyes, Mejía y Riguzzi (2013) para el caso nacional.

${ }^{13}$ En Erquizio (2010a, 2010b) se examinan las causas de la recesión de 2001-2003 y 2009, usando en ambos casos el ICEF para representar las recesiones, y se propone una ecuación de ciclo regional que contiene una variable que representa el mecanismo de propagación (Índice de Semejanza Recesiva y Producción Manufacturera como 
- Mayor vinculación con Estados Unidos, medida por el coeficiente de correlación entre el crecimiento de cada entidad federativa y el crecimiento de aquel país (CORREL 9406), o una medida más elaborada, como el coeficiente de elasticidad que señala la sensibilidad de los componente tendencia-ciclo de los Índices Coincidentes Estatales de México con respecto del componente tendencia-ciclo del Índice Coincidente de Estados Unidos (ЕLAST0310), mayor Índice de Semejanza Recesiva (ISREF09), y a menor Participación del Gasto Público en el PIBE (PGPD09), entonces menor tasa de crecimiento del PIBE en la recesión (IREF09).

- Menor vinculación con Estados Unidos, medida por el coeficiente de correlación entre el crecimiento de cada entidad federativa y el crecimiento de ese país (CORREL9406), o una medida más elaborada, como el coeficiente de elasticidad que señala la sensibilidad de los componente tendencia-ciclo de los Índices Coincidentes Estatales de México con respecto al componente tendencia-ciclo del Índice Coincidente de Estados Unidos (ELAST0310), menor Índice de Semejanza Recesiva (ISREF09), y a mayor Participación del Gasto Público en el PIBE (PGPD09), entonces mayor tasa de crecimiento del PIBE en la recesión (IREF09).

\section{Conclusiones}

La Gran Recesión de 2009, iniciada en Estados Unidos, tuvo grandes efectos en la economía mexicana y sus regiones, en el contexto de la creciente vinculación entre ambas economías expresada en la alta correlación entre sus tasas de crecimiento y la sincronización de sus ciclos económicos. Así, mientras que dicha recesión afectó relativamente más

porcentaje del PIBE, respectivamente), y como mecanismo de impulso la correlación cruzada entre las tasas de crecimiento del PIBE y del PIB de EE. UU. para ambas recesiones. Como resultado se obtienen coeficientes de determinación de $31 \%$ y $49 \%$ respectivamente. Los resultados reportados aquí, al usar información anual oficial de la tasa de crecimiento del PIBE para medir la recesión de 2009 e incorporar un mecanismo contracíclico, elevan el coeficiente de determinación de la ecuación de ciclo regional propuesta a 60\%. Lo que revela la pertinencia de lo desarrollado en este texto. 
Figura 7. Diagramas de dispersión en la recesión 2009
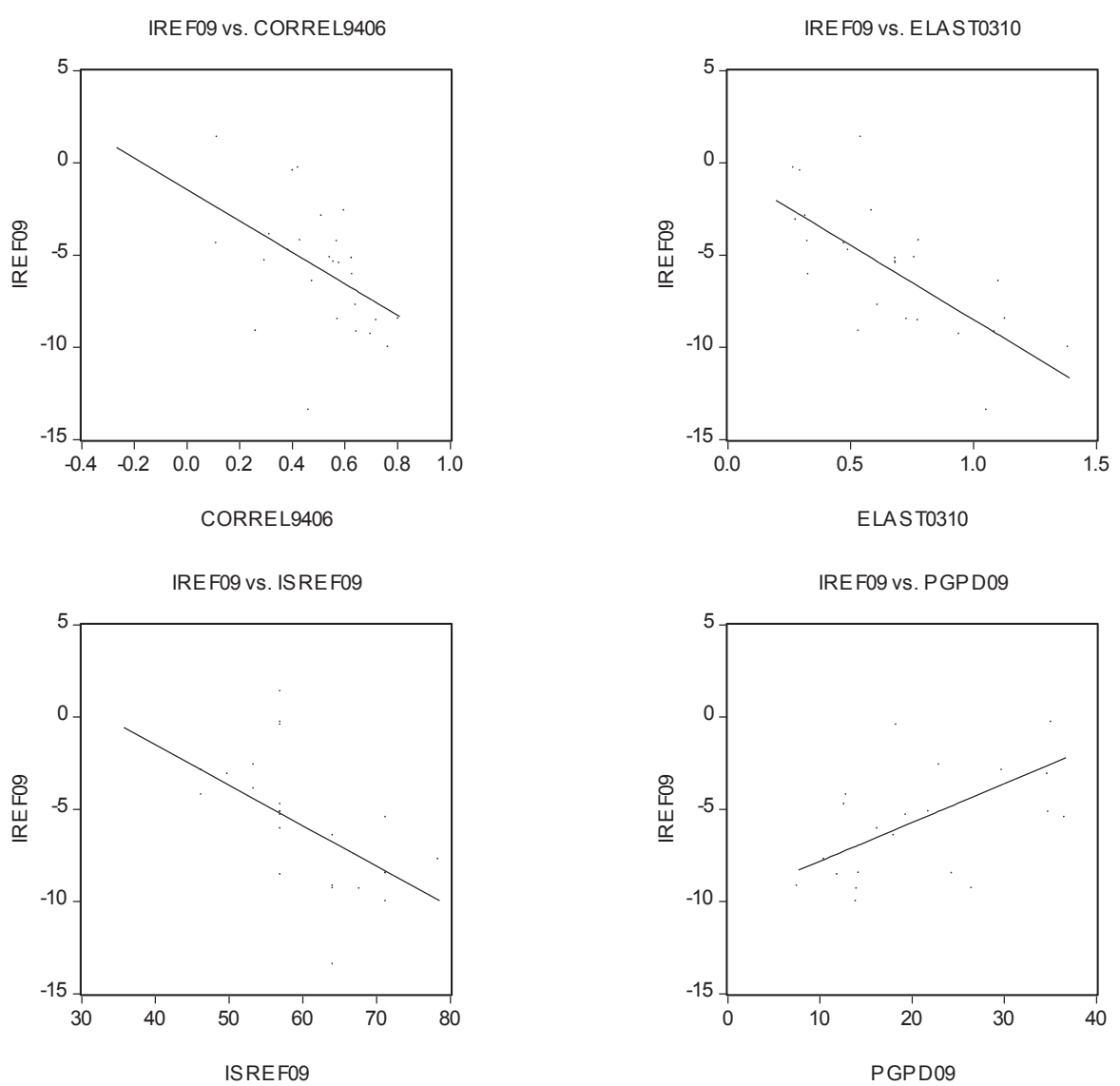

Fuente: Elaboración propia con Eviews.

a las entidades federativas, que como las del norte, el centro y el centronorte están más vinculadas al ciclo de EE. UU. y menos a las del sur, la expansión 2010-2012 fue más lenta en el sur y más rápida en las demás regiones.

La constatación de la diversidad recesiva regional de 2009 plantea el interrogante de otro de los motivos de ésta. Un primer acercamiento reveló que el perfil sectorial de las entidades federativas determina dicha diferenciación, pues las entidades federativas más manufactureras fueron las más afectadas, y las identificadas principalmente por su carácter agrícola o minero, lo fueron menos. Mientras que por el contrario, la diversidad regional observada en la expansión 2010-2012 muestra que son las 


\section{Cuadro 8. Estimaciones de la ecuación de ciclo regional en la Gran Recesión del 2009}

\begin{tabular}{|c|c|c|c|c|c|}
\hline \multicolumn{6}{|c|}{ Mecanismos del ciclo económico } \\
\hline \multicolumn{2}{|c|}{ Impulso } & Propagación & Contra-cíclico & $\begin{array}{c}R^{2} \\
\text { Ajustada }\end{array}$ & $\begin{array}{c}\text { Estadístico } \\
F\end{array}$ \\
\hline $\begin{array}{c}\text { Indicador de } \\
\text { correlación }\end{array}$ & $\begin{array}{c}\text { Indicador de } \\
\text { correlación }\end{array}$ & $\begin{array}{c}\text { Indicador de } \\
\text { semejanza recesiva }\end{array}$ & Gasto público & & \\
\hline $\begin{array}{c}\text { CORREL9406 } \\
-4.5^{*}\end{array}$ & & ISREF09 & PGPD09 & & \\
$(-1.7)$ & $-0.1^{*}$ & $0.17^{* * *}$ & 0.52 & 11.2 \\
\hline & ELAST0310 & $(-1.8)$ & $(3.2)$ & & \\
\hline & $-4.6^{* *}$ & $-0.1^{*}$ & PGPD09 & & \\
& $(-2.3)$ & $(-1.9)$ & $(1.8 *$ & 0.60 & 13.4 \\
\hline
\end{tabular}

La regresión incluye una constante. Los números entre paréntesis son los estadísticos t de los coeficientes, los asteriscos ***, ** y * denotan niveles de aceptación de 99\%, 95\% y $90 \%$ respectivamente. Las regresiones utilizan 30 observaciones, pues excluyen Campeche y Tabasco. Todas las ecuaciones pasan la pruebas de heterocedasticidad y normalidad.

Fuente: Elaboración propia con Eviews.

entidades más manufactureras las que encabezan dicha fase del ciclo económico nacional, mientras las entidades no manufactureras se expanden más lentamente.

Para profundizar en las causas de la diversidad recesiva regional en 2009, se recurre a la hipótesis de los ciclos clásicos de Wesley C. Mitchell, lo que permite proponer nuevos instrumentos analíticos como los Índices de Difusión Sincrónico y Diacrónico, y el Índice de Semejanza Recesiva, que identifican y distinguen las manifestaciones regionales de las recesiones clásicas nacionales.

Asimismo, se propone una ecuación de ciclo regional inspirada en la metáfora de Frish para explicar la diversidad de las tasas de crecimiento del PIв de las entidades federativas en la recesión y que se estimó mediante una regresión de corte transversal que incluye:

- un mecanismo de impulso (el coeficiente de correlación entre la tasa de crecimiento de la entidad federativa con la tasa de crecimiento de EE. UU.),

- un mecanismo de propagación (el índice de semejanza recesiva de la entidad federativa), y 
- un mecanismo contracíclico (el pocentaje de participación del gasto público con respecto del PIB de la entidad federativa).

Se encuentra así la evidencia de que, efectivamente, a mayor (menor) correlación con Estados Unidos, mayor (menor) semejanza recesiva y menor (mayor) participación del gasto público respecto del PIB, menor (mayor) tasa de crecimiento del PIBE en la Gran Recesión de 2009.

La propuesta presentada tiene alcances metodológicos, pues para medir y comparar los impactos regionales de las recesiones, propone nuevos índices en la tradición del enfoque de ciclos clásicos de Mitchell; y señala una manera de ponderar la importancia de los factores endógenos y exógenos en la determinación de la diversidad recesiva regional que los índices revelan.

\section{Bibliografía}

Agénor, Pierre-Richard, McDermott, J. y Prasad, E. S. (2000). Macroeconomic fluctuations in developing countries: Some stylized facts. The World Bank Economic Review, 14(2), 251-285.

Banamex-CITI. (2012). México. Indicadores regionales de actividad económica 2012.

Banco de México. (2011). Reporte sobre las economías regionales. México.

Banco de México. (2012). Informe anual 2011. México.

Bвva-Bancomer. (2007). Situación regional sectorial México.

BBva-Bancomer. (2012). Situación regional sectorial México.

Burns, A. y Mitchel, W. C. (1946). Measuring business cycles (No. 2). Studies in Business Cycles. Nueva York: National Bureau of Economic Research.

Cámara, S. (2008). Fluctuaciones cíclicas en México (1950-2003). Una perspectiva clásica de corto y largo plazos. En S. Cámara, E. Ortiz y M. Robles (Coords.), Reproducción y capital. Equilibrio y desequilibrio desde una perspectiva crítica de la economía (pp. 189-215). México: Ediciones eón, Universidad Autónoma Metropolitana-Azcapotzalco.

Calderón, C. (2012). Crisis y ciclos económicos de México de 1896 al 2010: Un análisis espectral. Argumentos, (70), 105-126.

Calderón, F. (2005). La convergencia en México de 1950 a 2000. Una aproximación de econometría espacial (Documento de investigación). México: Universidad Iberoamericana.

Cuadra, G. (2008). Hechos estilizados del ciclo económico en México (Documento de investigación, No. 2008-14). Banco de México. 
Cuevas, A., Messmacher, M. y Werner, A. (2003). Sincronización macroeconómica entre México y sus socios comerciales del TLCAN (Documento de investigación, No. 2003-1). Banco de México.

Chávez, J. C., Rodríguez, R. y Fonseca, F. de J. (2010). Vacas gordas y vacas flacas: La política fiscal y el balance estructural en México, 1990-2009, Estudios Económicos, 25(2), 309-336.

Delajara, M. (2011a). Con movimiento regional del empleo durante el ciclo económico en México. El Trimestre Económico, LXXVIII(3), 311, 613-642.

Delajara, M. (2011b). Sincronización entre los ciclos económicos de México y Estados Unidos. Nuevos resultados con base en el análisis de los índices coincidentes regionales de México. México: Banco de México.

Delajara, M. (2013). Comovimiento y concordancia cíclica del empleo en los estados mexicanos. Economía Mexicana. Nueva Época, xxII(2), 297-340. Del Negro, M. y Ponce, A. (1999). Is North America an optimal currency area? Regional versus national shocks in the United States, Canada and México. México: Instituto Tecnológico Autónomo de México.

Díaz, E. y Mendoza, M. A. (2012). Crisis y recuperación económica en los estados de la frontera norte. Un análisis de los ciclos económicos. Estudios Fronterizos. Nueva Época, 13(25), 89-129.

Erquizio, A. (2001). Índice líder y ciclo económico en México. Economía Informa, (301), 56-62.

Erquizio, A. (Octubre, 2002). Recesiones regionales: Sonora, 1995 y 2000. XII Coloquio Mexicano de Economía Matemática y Econometría, Universidad Autónoma Metropolitana, México, D. F..

Erquizio, A. (2006a). Ciclos Económicos en México (Colección Textos Académicos, No. 62). México: Editorial Universidad de Sonora.

Erquizio, A. (2006b). Ciclos económicos en la frontera norte de México: 19802005. En C. Bocanegra y M. Á. Vázquez (Coords.), Desarrollo regional y local. Tendencias, retos y estrategias (pp. 45-74). Hermosillo: Unison.

Erquizio, A. (2007a). Identificación de los ciclos económicos en México, 19492006. Problemas del Desarrollo, 38(150), 235-250.

Erquizio, A. (2007b). Ciclos regionales y políticas públicas en México. En C. Bustamante, C. Hernández, S. Rodríguez y R. M. de L. Sánchez (Coords.), Reconstruir el desarrollo regional de México ante la recomposición del mundo. México: Asociación Mexicana de Ciencias para el desarrollo Regional A.C.

Erquizio, A. (2008). Ciclos económicos del Estado de México en el contexto regional: 1980-2005. En P. Mejía, O. Rodríguez y L. del Moral (Coords.), Actividad económica del Estado de México. Volumen I. Desempeño productivo y sector externo, (pp. 25-56). Toluca: Biblioteca Mexiquense del Bicentenario, Gobierno del Estado de México. 
Erquizio, A. (2010a). Recesiones regionales en México: Diversidad y causas. Análisis económico. Revista de Ciencias Sociales y Humanidades de la Universidad Autónoma Metropolitana, 25(60), 81-113.

Erquizio, A. (2010b). Gran Recesión 2008-2009 en EE. UU. y México: Un enfoque regional. Paradigma Económico. Revista de Economía Regional y Sectorial, 2(2), 5-40.

Erquizio, A. y Gracida, J. (2010). Las recesiones recientes en Sonora y Sinaloa. Una comparación. Vértice Universitario, 9(45), 3-12.

Erquizio, A. y Ramírez, R. (2012). Crecimiento, recesiones y política fiscal en México: Una perspectiva regional. En A. Sánchez e I. Sánchez (Coords.), 1er Congreso Iberoamericano sobre Desarrollo Regional: Posicionamiento Mundial y Estrategias, y $17^{\circ}$ Encuentro Nacional sobre Desarrollo Regional en México, México: Asociación Mexicana de Ciencias para el Desarrollo Regional A. C.

Federal Reserve Economic Data. (Enero, 2014). Recuperado de la base datos de $<$ http://research.stlouisfed.org/fred2/>.

Félix, G. y Dávila, A. (2008). Apertura comercial y demanda en el crecimiento de las entidades federativas de México. Comercio Exterior, 58(4), 258-270.

Fragoso, E., Herrera, J. y Castillo, R. (2008). Sincronización del empleo manufacturero en México y Estados Unidos. Economía Mexicana, XVII(1), 5-47.

Frisch, R. (1933). Propagation problems y impulse problems in dynamic economics. Economic Essays in Honour of Gustave Cassel. Londres: Allen \& Unwin.

Gámez, C. e Ibarra-Yúnez, A. (2009). El ciclo político oportunista y el gasto de los estados mexicanos. Gestión y Política Pública, XVIII(1), 39-65.

Heath, J. (2011). La identificación de los ciclos económicos en México: Treinta años de evidencia. Realidad, datos y espacio. Revista Internacional de Estadística y Geografía, 2(2), 18-31.

Instituto Mexicano para la Competitividad. (2008). Índice de Competitividad Estatal 2008. Aspiraciones y realidad: Las agendas del futuro. México: Instituto Nacional de Estadística y Geografía. (Febrero, 2014). Recuperado de < http:// www.inegi.org. $\mathrm{mx} />$.

Jarsulic, M. (1993). Recent developments in business cycle theory. Review of Political Economy, 5(3), 334-363.

Louçã, F. (2001). Intriguing pendula: Founding metaphors in the analysis of economic fluctuations. Cambridge Journal of Economics, 1(25), 25-55.

Lucas, R. (1985). Comprendiendo los ciclos económicos. Cuadernos Económicos del ICE, 30, 45-64.

Mejía, P. (1999). Classical business cycles in Latin America: Turning point, asymmetries and international synchronization. Estudios Económicos, 14(2), 265-297.

Mejía, P. (2003). Regularidades empíricas en los ciclos económicos de México: Producción, inversión, inflación y balanza comercial. Economía Mexicana. Nueva Época, XII(2), 231-274. 
Mejía, P. (2007). Expansions and recessions in the Mexican states: A classical business cycles approach. Panorama Económico, III(5), 7-38.

Mejía, P. (2011). Sincronización nacional e internacional de la manufactura de los estados de México. En P. Mejía y M. E. Morales (Coords.), Integración y recesión económica en el binomio México-Estados Unidos (pp. 211-240). México: Universidad Autónoma del Estado de México.

Mejía, P., Ochoa, S. y Díaz, M. Á. (2013). De la recesión a la recuperación: Producción y empleo en México y el Estado de México. Revista Problemas del Desarrollo, 173(44), 133-162.

Mejía, P. y Erquizio, A. (2012). Expansiones y recesiones en los estados de México. México: Pearson, Universidad Autónoma del Estado de México, Universidad de Sonora.

Mejía, P. y Campos, J. (2011). Are the Mexican states and the United States business cycles synchronised? Evidence from the manufacturing production. Economía Mexicana. Nueva Época, xx(1), 79-112.

Mejía, P., Rodríguez, O. y Del Moral, L. (Coords.). (2008). Actividad económica del Estado de México. Volumen I. Desempeño productivo y sector externo. Toluca: Biblioteca Mexiquense del Bicentenario, Gobierno del Estado de México.

Mejía R., P. y Mejía R., A. (2007). Fluctuaciones cíclicas en México y en el Estado de México en el contexto del TLCAN: ¿Cuáles son los hechos? Economía, Sociedad y Territorio, $\operatorname{VII}(25), 103-127$.

Mejía, P., Gutiérrez, E. y Pérez, J. (2006). Los claroscuros de la sincronización internacional de los ciclos económicos: Evidencia sobre la manufactura de México. Ciencia Ergo Sum, 13(2), 133-142.

Mejía, P., Gutiérrez, E. y Farías, C. (2006). La sincronización de los ciclos económicos de México y Estados Unidos. Investigación Económica, 65(258), 15-45.

Mejía, P., Ochoa, S. y Díaz, M. Á. (2013). De la recesión a la recuperación: Producción y empleo en México y el Estado de México. Problemas del Desarrollo. Revista Latinoamericana de Economía, 44(173), 133-162.

Mitchel, W. C. (1913). Business cycles. Estados Unidos: University of California Press.

Mitchel, W. C. (1915). The making and using of index numbers. Bulletin of the US Bureau of Labor Statistics.

Mitchel, W. C. (1927). Business cycles: The problem and its setting. Nueva York: National Bureau of Economic Research.

Mitchel, W. C. (1951). What happens during business cycles. Nueva York: National Bureau of Economic Research.

Moreno, J. (1995). Un sistema de indicadores de seguimiento de corto plazo para la economía mexicana: Análisis, construcción y experiencias. Ejecutivos de Finanzas, marzo. 
Palacios, Ó. (2009). Impulsos fiscales y política contracíclica en México. Finanzas Públicas, 1(2), 93-110.

Ponce, A. (2001). Determinantes de los ciclos económicos en México: ¿Choques agregados o desagregados? Gaceta de Economía, (12), 117-155.

Ramírez, R. y Erquizio, A. (2012). Análisis del ciclo político electoral a partir de variables de gasto público por entidad federativa en México, 1993-2009. Paradigma Económico. Revista de Economía Regional y Sectorial, 4(2), 5-27.

Reyes, M. R., Mejía, P. y Riguzzi, P. (2013). Ciclo político presupuestal y gobiernos con y sin mayoría en México, 1994 y 2006. Economía, Sociedad y Territorio, XIII(41), 79-119.

Slutsky, E. (1937). The summation of random causes as the source of cyclic processes. Econometrica, 5(2), 105-146.

Torres, A. (2002). Estabilidad en variables nominales y el ciclo económico: El caso de México. Gaceta de Economía, II, 61-116.

The Conference Board. (Enero, 2014). Recuperado de < http://www.conferenceboard.org/.>.

Villagómez, A. y Navarro, L. (Marzo, 2010). Política fiscal contracíclica en México durante la crisis reciente: Un análisis preliminar (Documento de trabajo, No. 475). México: Centro de Investigación y Docencia Económica. 
